\title{
AUTO INTENSITY CONTROL OF A STREET LIGHT BY USING PV CELL
}

\author{
C. Hari Prasad, C. Sesha Shayini, V. Shirisha, T. Veera Shankar \\ Department of EEE \\ SSE College, Puttaparthi, AP, India
}

Mr. N. Pavan Kumar, M.E

Asst. Professor, HOD, Dept. of EEE

SSE College, Puttaparthi, AP, India

\begin{abstract}
The 21st century is striving hard to save electrical energy. Streetlights are essential, but expensive, therefore there is need to optimize the system in a way that it is affordable and efficiently conserves energy. Manually controlling the streetlights is a time taking and tedious process. Working in such manner could sometimes result in large disasters and destructions. The main problem that manual controls on the street lights face is that there would be a lot time taking during evening times when they are to be switched $\mathrm{ON}$ and a significant waste of energy is done at morning at all could not be turned OFF together at once. Another way in which the wastage is done is that at midnights lights glow at full intensity although there is not much traffic.
\end{abstract}

Therefore, there is a need to come up with a system which overcomes the problems of existing systems. A system which reduces manual control and would efficiently save energy. This could be done by using low power, robust and efficient components.

Key words: Solar panel, Atmega328 Arduino UNO, RTC module and LDR.

\section{INTRODUCTION}

The project is designed for LED based streetlights with auto intensity control using solar power from photovoltaic cells. As awareness for solar energy is increasing, more and more individuals and institutions are opting for solar energy. Photovoltaic panels are used for charging batteries by converting the sunlight into electricity. A charge controller circuit is used to control the charging and prevent the battery to overcharging from the solar panel.
Intensity of streetlights is required to be kept high during the peak hours. At late night intensity of light should be max after some time the intensity can be reduced progressively till morning to save energy. Thus final it completely shuts down at morning 6 , and again resumes at $6 \mathrm{pm}$ in the evening. The process repeats every day.

Battery charger should have over voltage protection, short circuit protection and reversed polarity protection. The microcontroller contains programmable instructions which controls the intensity of streetlights based on the PWM (Pulse width modulation) signals generated. To generate PWM signal at different time we used RTC.

Real-time clock (RTC) counts seconds, minutes, hours, date of the month, month, day of the week, and year with leap-year. RTC will consume power from microcontroller. RTC is use to detect Automatic power-fail in the circuitry.

From the dusk with full intensity till $11 \mathrm{pm}$ from $6 \mathrm{pm}$ and at 6'o clock to 8 'o clock $60 \%, 8$ 'o clock to 12 'o clock $70 \% 12$ mid night it is $100 \%$ duty cycle, 1 'o clock to 4'o clock $60 \%$, 4'o clock to 6'o clock $60 \%$ and finally OFF at the dawn.

LED lights are the future of lighting, because of their low energy consumption and long life they are fast replacing conventional lights world over Hence we used LEDs to control the intensity of light

\section{EXISTING SYSTEM}

Since the HID lamps are not cost effective and not reliable, smart street light system has overcome by replacing the HID lamps with LED. To control and maintain complex street lighting system more economically, various street light control systems are developed. These systems are developed to control and reduce energy consumption of a town's public lighting system using different technologies which uses IR motion sensors to detect the vehicle 
movement after which the street light begins to glow. As the vehicle moves, the street light that was glowing switches off and the following lights begins to glow. a) Arduino Uno R3 Arduino Uno R3. There are various input and output pins where 14 of them are digital pins with serial transfer and external interrupts and PWM (Pulse Width Modulation) pins and 6 analog pins. Arduino differs from all the preceding boards which does not use the FTDI USB-to-serial driver chip. b) Infrared sensor an infrared sensor is an electronic device that emits in order to sense some aspects of the surroundings. An IR sensor can measure the heat of an object as well as detects the motion. These types of sensors measures only infrared radiation, rather than emitting it that is called as a passive IR sensor. Usually in the infrared spectrum, all the objects radiate some form of thermal radiations. These types of radiations are invisible to our eyes that can be detected by an infrared sensor. The emitter is simply an IR LED and the detector is simply an IR photodiode which is sensitive to IR light of the same wavelength as that emitted by the IR LED. When IR light falls on the photodiode. The resistances and these output voltages, change in proportion to the magnitude of the IR light received.

\section{PROPOSED SYSTEM}

In this fast-moving world with new scientific era electricity such that electrical energy plays a very vital role. New developments and new inventions are made which focus on saving this non-renewable electrical energy.

Presently street lights mounted uses "electrical energy" along with "compact fluorescent lamp" which has very high electricity consumption. In this making an effort on saving electricity by using solar power, LED, and RTC for street lightning. This project is about switching of street lights in the evening when there is dark using solar energy stored but focuses on switching only within the timeslots given and then is automatically switched off when, which shows a perfect example of energy saving. PWM is required mainly for intensity controlling of led. LDR is a light dependent resistor which is having very high resistance, whose resistance decreases when light impinges on it. This kind of sensors is commonly used for light. Sensors circuit on open areas to control street lamps. The LDR is mainly used to difference between day and night light.

Using $18 \mathrm{~V}$ solar panel we will charge $12 \mathrm{~V}$ battery. The charge controller circuit can prevent the battery to flow high current through it after than we will convert $12 \mathrm{~V}$ to $5 \mathrm{~V}$ using voltage divider circuit.
Using RTC can generate seconds, minutes, hours, date of the month, month, day of the week and year with leap year. To RTC can generate seconds, minutes, hours, date of the month, day of the week and year with leap year.

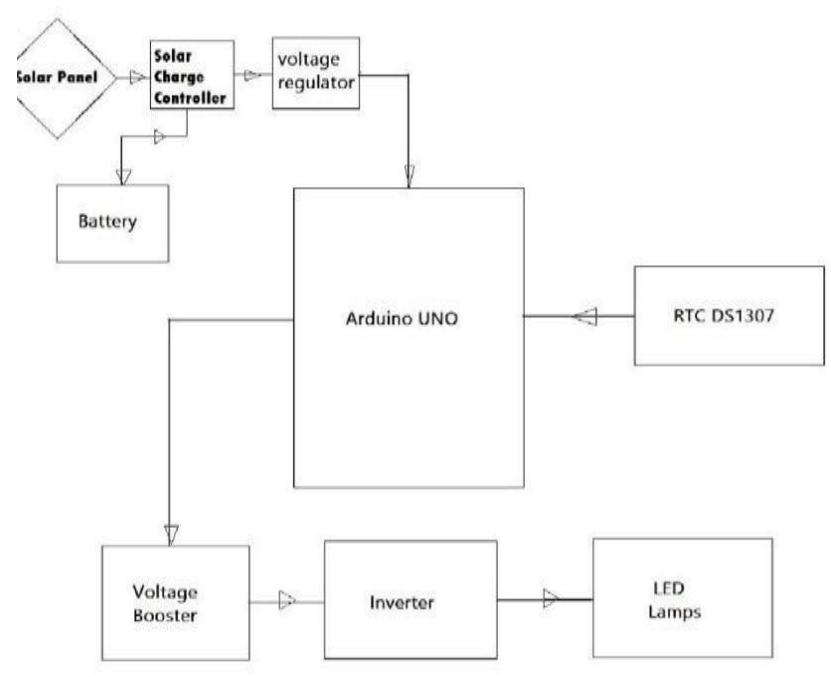

Fig: Block Diagram

\section{a. Solar Panel}

A solar panel is a collection of solar cells. The solar panel converts the solar energy into electrical energy. Output of the solar panel is its power which is measured in terms of Watts or Kilo watts. Solar power uses multiple reflectors to collect more sun's thermal energy. Thermal energy collected through the day to perform different operations. Performance of the solar panel depends on a number of factors like climate, conditions of the sky, orientation of the panel, intensity and duration of sunlight and its wiring connections.

\section{b. Charge Controller Circuit}

If the battery voltage is below $12 \mathrm{~V}$, then the current from LM317 IC flows to the battery. The current flow to the battery stops when the battery voltage rises to $13.5 \mathrm{~V}$. Hence charge controller circuit will prevent the battery to flow high current through it.

\section{c. Rechargeable Battery}

A rechargeable battery, storage, secondary battery or accumulator is a type of electrical battery which can be charged, discharged into a load, and recharged many times, while a non-rechargeable or primary battery is supplied fully charged and discarded once discharged. Several different combinations of electrode materials and electrolytes are used, including lead-acid nickel cadmium (NiCad), nickel metal hydride (Ni-MH), lithium ion (Li-ion), and lithium ion polymer ( $\mathrm{Li}$ ion polymer). 


\section{d. Voltage Regulator}

A voltage divider is a simple circuit which turns a large voltage into a smaller one. Using just two series resistors and an input voltage, we can create an output voltage that is a fraction of the input. Voltage dividers are one of the most fundamental circuits in electronics equation of circuit is shown in fig.

\section{e. Arduino UNO}

Micro-controller will control the intensity of light at different time slots. Micro controller circuit will generate PWM waves at a particular time using RTC (Real Time Clock) these system provide sets of digital and analog I/O pins that can be interfaced to the street light circuit. Operating voltage of Arduino UNO is $5 \mathrm{v}$ so that we will convert $12 \mathrm{v}$ from Battery to $5 \mathrm{v}$.

\section{f. Light Dependent Resistor (LDR)}

Light dependent resistor is used to detect change in light intensity or as alight sensor. LDR is basically a variable resistor. LDR resistance changes with the change in intensity of light. If intensity of light falling on LDR is high, LDR will have low resistance. When intensity of light increases, LDR offers high resistance. Hence there is a inverse relationship between intensity of light and resistance of LDR. LDR is a resistor and its resistance vary according to the amount of light falling on its surface.

\section{g. $\quad$ Real Time Clock (RTC) DS1307}

Real Time Clock or RTC is a system that keeps track of the current time and can be used in any device which needs to keep accurate time. You can also keep tracking the exact time without using RTC systems, but RTCs have some important advantages. Here are some of these advantages: i) Low power consumption

ii) Releasing system time from time calculation iii) High accuracy DS1307 module is one of the most affordable and common RTCs modules. It can accurately keep track of seconds, minutes, hours, days, months, and years.

\section{WORKING}

The system consists of two circuits, charge control circuit and the load intensity circuit. The charge control circuit consists of 4 parts over charge indication, overload detection with protection and low battery voltage detection with indication ICLM317t adjustable three terminal positive-voltage regulator. And it is capable of supplying more than $1.5 \mathrm{~A}$ over an output voltage range of $1.25 \mathrm{v}$ to $37 \mathrm{~V}$.
This automatic battery charger circuit design mainly involves two sections. Power supply section and load comparison section.

If the battery voltage is below $12 \mathrm{~V}$, then the current from LM317 IC flows through the resistor R5 and diode D5 to the battery. At this time Zener diode D6 will not conduct because battery takes all the current for charging.

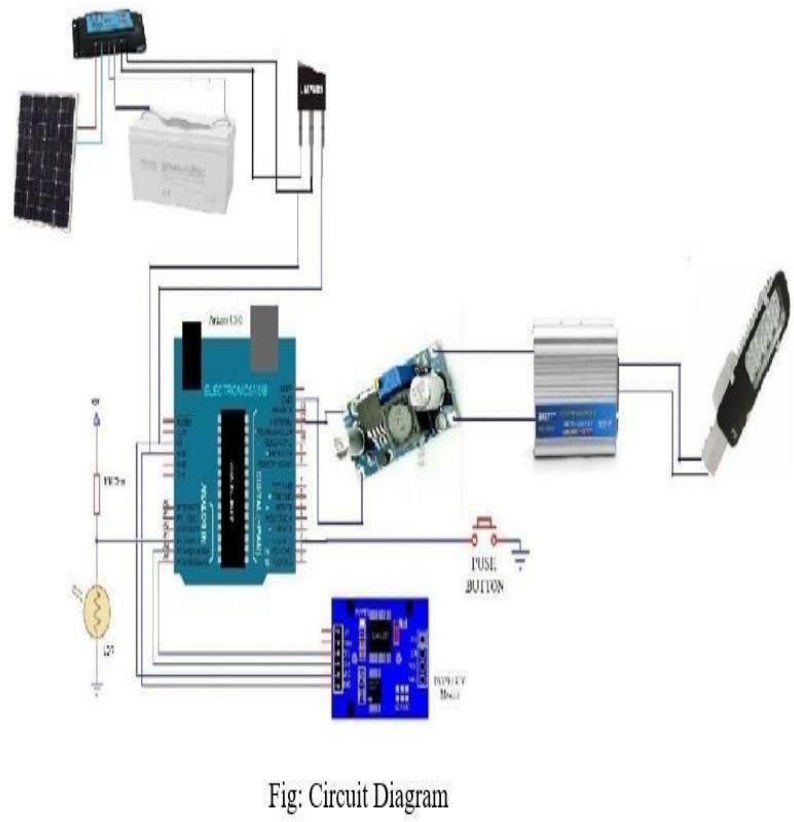

When the battery voltage rises to $13.5 \mathrm{~V}$, the current flow to the battery stops and Zener diode gets the enough breakdown voltage and it allows the current through it. Now the base of the transistor gets the sufficient current to turn on so that the output current from LM317 voltage regulator is grounded through the transistor Q1. As a result Red LED indicates the full of charge.

The load intensity control part consists of the controller - Arduino UNO which control the power supply to the load through the transistor and RTC (real time clock). RTC can generate PWM waves at particular time .so as to vary the intensity of the LED's. Here an array of LED's is connected as the load.

After making the connections and uploading the code to Arduino, turn on the Power supply to the project. Initially, the Arduino runs in RTC Mode where there are two times set in the code: the ON TIME and the OFF TIME.

Arduino compares the ON TIME with the time from RTC Module and when they match, the LED is turned ON. After this, the Arduino waits for the OFF TIME and once the time from RTC Module reaches the OFF TIME, the LED is turned OFF. 
During anytime of this operation, if the button (connected as an external interrupt to Pin 2) is pushed, the Arduino enters LDR Mode. In this mode, the Arduino reads the value of the LDR from A3 and based on the value, it adjusts the intensity of the LED.

\begin{tabular}{|c|c|c|c|c|c|}
\hline Timi & 6'o to & 8'o to & 12 'o & 1'o & 4'o \\
\hline ngs & $\begin{array}{l}\text { 8'o } \\
\text { clock }\end{array}$ & $\begin{array}{l}\text { 12'o } \\
\text { clock }\end{array}$ & clock & $\begin{array}{l}\text { 4'o } \\
\text { clock }\end{array}$ & $\begin{array}{l}\text { 6'o } \\
\text { clock }\end{array}$ \\
\hline $\begin{array}{l}\text { Inten } \\
\text { sity }\end{array}$ & $60 \%$ & $80 \%$ & $100 \%$ & $80 \%$ & $60 \%$ \\
\hline
\end{tabular}

\section{RESULT AND CONCLUSION}

The solution to energy conservation is to eliminate time slot and introduce a system that could sense brightness environment and act accordingly so that seasonal change would not affect the intensity of streetlights. Also, LED's should replace HID lamps due to their dimming feature, another reason is that they are more reliable.

The solar energy is one of the important and major renewable sources of energy and has also proven it useful in functioning of applications like streetlights.

Solar powered automatic street light controller is one of the applications of electronics to increase the facilities of life. The use of new electronic theories has been put down by expertise to increase the facilities given by the existing appliance. Here the facility of ordinary streetlight is increased by the making it controlled automatically. The charge control is necessary in order to achieve safety and increase the capacity of the battery. In cities, currently thousands of streetlights are operated, and the yearly electricity maintenance cost is very high. It saves around $40 \%$ of electricity from per streetlight. So, throughout the world if we use this concept then it will eliminate the energy crisis to a larger extent. It is eco-friendly and utilizes the renewable source of energy very well.

\section{ACKNOWLEDGEMENT}

It is us privilege to express our sincerest regards to our project coordinator and Head of Department Mr. N. Pavan Kumar, for their valuable inputs, able guidance, whole -hearted cooperation throughout the duration of our project.

We deeply express thankful for encouraging and allowing us to present the project on the topic "AUTO INTENSITY CONTROL OF A STREET LIGHT BY USING PV CELL"

\section{REFERENCE}

[1] R. Santhosh Kumar, Dr. Prabu, S. Vijaya Rani and P. Venkatesh 2015. Design and Implementation of an Automatic Solar Panel Based Led Street Lighting System Using Zigbee and Sensor, MiddleEast Journal of Scientific Research 23 (4): 573-579, 2015.

[2] Liu, D., S. Qi, T. Liu, S.Z. Yu and F. Sun, 2009. The design and realization of communication Technology for street lamps control system, in Proc.4th Int. Conf. Comput. Sci.

[3] Costa, M.A.D., G.H. Costa, A.S. Dos Santos, L.Schuch and J.R. Pinheiro, 2009. A high efficiency autonomous street lighting system based on solar energy and LEDs, in Proc. Power Electron. Conf. Brazil, pp: 265273.

[4] Deepu Vijay M., Kamlesh Shah, G.Bhuvaneswari and Bhim Singh. LED Based Street Lighting with Automatic Intensity Control Using Solar PV. 2015 IEEE IAS Joint Industrial and Commercial Power Systems/Petroleum and Chemical Industry Conference (ICPSPCIC).

[5] F. J. Nogueira, L. A. Vitoi, L. H. Gouveia, C. G. Casagrande, D. P. Pinto and H. A. C. Braga. "Street lighting LED luminaires replacing high Pressure sodium lamps: Study of case". IEEE/IAS International Conference on Industry Applications (INDUSCON), Juiz de Fora, Brazil, 2014. 
International Journal of Engineering Applied Sciences and Technology, 2020

Vol. 4, Issue 12, ISSN No. 2455-2143, Pages 691-695

Published Online April 2020 in IJEAST (http://www.ijeast.com)

[6]Mokhtar Ali,Mohamed EmadAbdelkarim, Jaber Jaber A. Abu QahouqandAbdelali El Aroudi“Design and Development of Energy-Free SolarStreet LED Light System” IEEE 2011

[7] Gustavo W. Denardin, Carlos H. Barriquello, Alexandre Campos, Rafael A.

pinto, "Control Network for Morden Street Lighting Systems", IEEE symposium on Industrial Electronics (ISIE), (2011), PP.1282-1289.

[8] John M. Anderson "First Electronic Street Lamps" IEEE Power Engineering Review, pp.39-40, Mar.2000.

[9] M. Srikanth and K. N. Sudhakar, "Zigbee based remote control automatic street light system," Int. J. Eng. Sci. Comput., pp. 639-643, 2014.
[10] C. Bhuvaneswari, R. Rajeswari and C. Kalaiarasan, "Analysis of solar energy based street light with auto tracking system," Int. J. Adv. Res. Electr. Electron. Instrum. Eng., vol. 2, no. 7, pp. 3422-3428, 2013

[11] P. C. Cynthia, V. A. Raj and S. T. George, "Automatic street light control based on vehicle detection using arduino for power saving applications," Int. J. Electron. Electr. Comput. Syst., vol. 6, no. 9, pp. 297-295, 2017

[12] K. S. Sheela and S. Padmadevi, "Survey on street lighting system based on vehicle movements," Int. J. Innovative Res. Sci. Eng. Technol., vol. 3, no. 2, pp. 9220-9225, 2014. 